\title{
Pumping system design challenges for high-density iron ore tailings with highly variable slurry rheology
}

\author{
Andres Ortiz Paterson and Cooke Australia Pty Ltd, Australia \\ Alan Rosewall Paterson and Cooke Australia Pty Ltd, Australia \\ Peter Goosen Paterson and Cooke Consulting Engineers Pty Ltd, South Africa
}

\section{Abstract}

Fine iron ore tailings slurry is commonly deposited in tailings storage facilities across the Pilbara region of Western Australia. Many of these mines process ore from a combination of deposits such as Bedded Iron Deposits (BID), Channel Iron Deposits (CID) and Detrital Iron Deposits (DID), mixing the feed to obtain the product under contract. Each one of these ore deposits presents different particle size distribution and mineralogy, including clay composition, which translates into highly variable properties (and in particular, rheology) for the tailings slurry. This variability in the slurry can occur over a mining cycle (several weeks) or even over the course of a day.

The iron ore process plants typically aim to manage the output solids concentration through the operation of the tailings thickener/s. Thickened tailings systems, due to the relatively high slurry concentration, can experience large changes in slurry rheology with relatively small variations in solids concentration or mineralogy. This high variability in the slurry rheology may became problematic for the thickener control system, operations personnel and finally the tailings pipeline.

This paper discusses some of the challenges encountered when designing high-density tailings pumping systems where the expected rheology "envelope" is significantly wide. Additionally, comments are made on key considerations for the selection of pumping equipment and the pipeline to be able to cope with these potential rheology variations throughout the life of the project.

\section{Introduction}

The Pilbara region, in the north of Western Australia, is known to hold some of the world's largest iron ore deposits. Such sources of iron ore also offer a large diversity of mines and consequently ore deposits, mineralogy, water chemistry and tailings deposition arrangements. This becomes a challenge for the tailings pumping system which must reliably handle whatever is received from the process plant. In other words, the tailings pumping system must not become a constraint or bottleneck for the process plant.

Our experience with slurry pipeline systems for iron ore tailings from several of these mines indicates that there is no such thing as a "one-size-fits-all" solution for tailings slurry handling. This is largely due to the high variability of slurry rheology rather than particle size distribution or other design parameters. In some cases, the slurry and overall tailings containment strategy favors low concentration slurries, where the slurry rheology does not vary significantly within the design range. However, the most common scenario is that water conservation as well as the tailings management plan require designing for "intermediate" to "high" slurry concentrations. This is the focus of this paper. 
In this context, we define "low", "intermediate" and "high" concentration as previously presented by Goosen and Paterson, 2014, with a proposed modification to the division between intermediate concentration and high concentration: We now propose that the intermediate to high concentration boundary is defined by the locus of $1.5 \mathrm{KPa} / \mathrm{m}$ pipeline friction pressure gradient. This criterion is considered to differentiate between conditions under which we would generally expect a settled bed to be transported (pressure gradient > $1.5 \mathrm{KPa} / \mathrm{m}$ ) and where a stationary bed may occur (pressure gradient $<1.5 \mathrm{KPa} / \mathrm{m}$ ). This classification is illustrated in Figure 1. It should be noted with these definitions, the actual concentration values differentiating low, intermediate and high concentration will vary not only with slurry properties but also with pipe diameter.

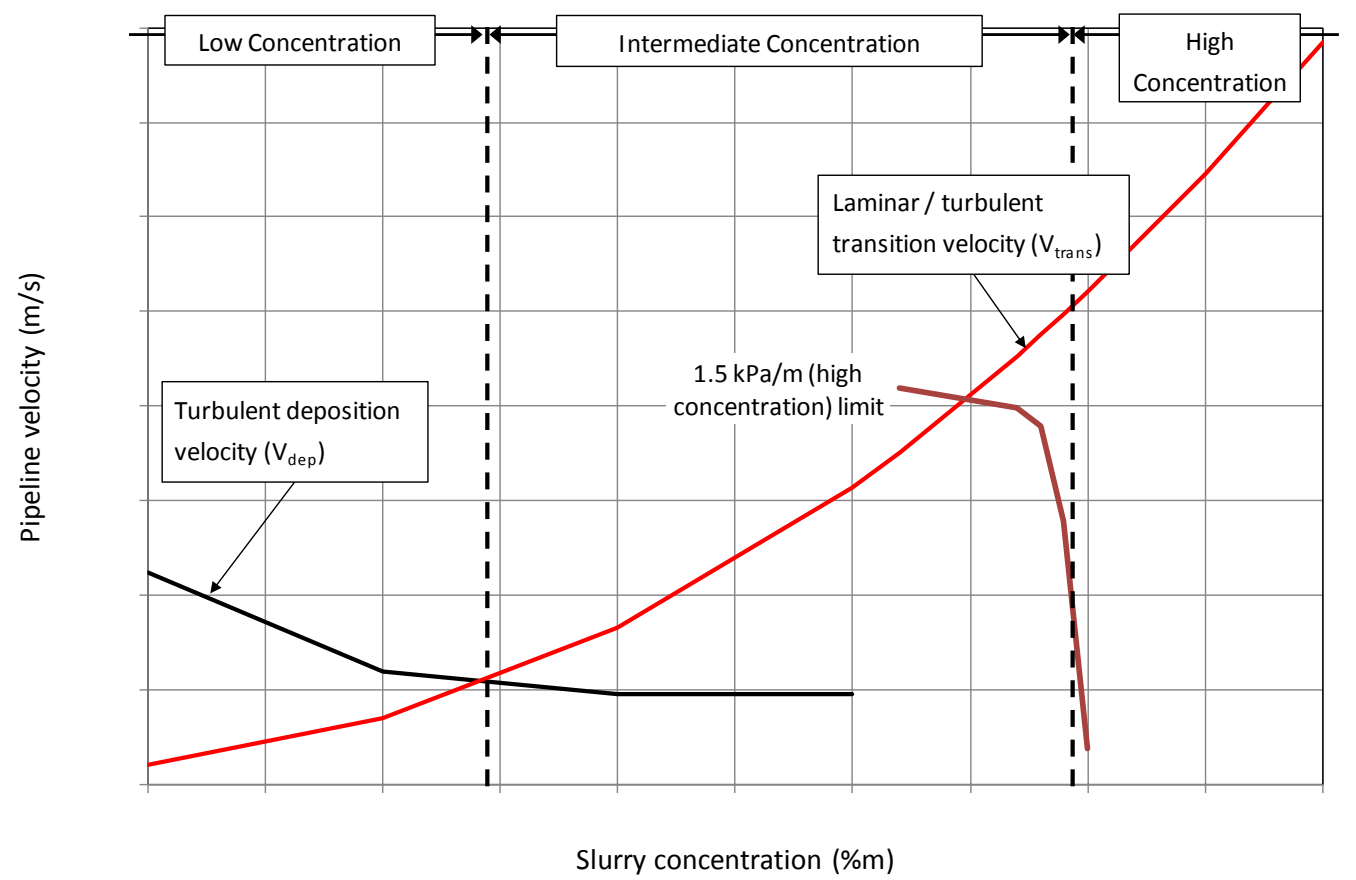

Figure 1 Low, intermediate and high concentration classification, and associated slurry flow behaviour

Table 1 Low, intermediate and high concentration classification, and associated slurry flow behaviour

\begin{tabular}{|c|c|c|}
\hline Classification & Defining limits & Pipeline flow behaviour \\
\hline Low concentration & $\begin{array}{l}\text { Upper limit is defined by the intersection of the turbulent } \\
\text { deposition velocity trend, and the laminar / turbulent } \\
\text { transition velocity trend. }\end{array}$ & $\begin{array}{l}\text { Pipeline flow is always turbulent. } \\
\text { Deposition occurs in the turbulent } \\
\text { flow regime (generally a stationary } \\
\text { deposit). }\end{array}$ \\
\hline $\begin{array}{l}\text { Intermediate } \\
\text { Concentration }\end{array}$ & $\begin{array}{l}\text { Lower limit is defined as described above for upper limit } \\
\text { of low concentration region. } \\
\text { Upper limit is defined by the } 1.5 \mathrm{kPa} \text { friction pressure } \\
\text { gradient locus. }\end{array}$ & $\begin{array}{l}\text { Pipeline flow may be turbulent or } \\
\text { laminar. } \\
\text { Deposition occurs in the laminar } \\
\text { flow regime (deposit may be } \\
\text { stationary or sliding). }\end{array}$ \\
\hline $\begin{array}{l}\text { High } \\
\text { concentration }\end{array}$ & $\begin{array}{l}\text { Lower limit is defined by the } 1.5 \mathrm{kPa} \text { friction pressure } \\
\text { gradient locus. }\end{array}$ & $\begin{array}{l}\text { Pipeline flow is always laminar (for } \\
\text { practical pipeline operating } \\
\text { velocities). } \\
\text { Flow possible at low velocities } \\
\text { without stationary deposit. }\end{array}$ \\
\hline
\end{tabular}


The intermediate to high concentration range brings the challenge of designing for a large range of slurry rheology, from typical yield stress of 20 to even more than $100 \mathrm{~Pa}$ in some cases. This must be combined with throughput variations as well as different particle size distributions, for example during upset conditions at the process plant.

\section{$2 \quad$ Tailings slurry properties}

Paterson and Cooke have undertaken several test campaigns for tailings sourced from different types of Pilbara iron ores, as part of the design of tailings pipeline systems. The following table summarizes the solids characterization of some of these samples.

Table 2 Iron ore tailings solids characterisation

\begin{tabular}{|c|c|c|c|c|c|c|}
\hline Sample No. & Ore Type & Solids SG & Top Size (mm) & d90 particle size $(\mu \mathrm{m})$ & $+75 \mu \mathrm{m}$ fraction & $-45 \mu \mathrm{m}$ fraction \\
\hline 1 & Mixed* & 3.6 & 1.0 & 125 & $19 \%$ & $70 \%$ \\
\hline 2 & Mixed* & 3.5 & 1.0 & 110 & $18 \%$ & $70 \%$ \\
\hline 3 & CID & 3.6 & 1.0 & 120 & $21 \%$ & $65 \%$ \\
\hline 4 & CID & 3.5 & 1.0 & 125 & $24 \%$ & $62 \%$ \\
\hline 5 & CID & 3.7 & 1.0 & 170 & $24 \%$ & $57 \%$ \\
\hline 6 & CID & 3.4 & 1.0 & 130 & $20 \%$ & $70 \%$ \\
\hline 7 & BID & 3.4 & 1.0 & 130 & $20 \%$ & $69 \%$ \\
\hline 8 & Mixed* & 4.1 & 1.2 & 150 & $24 \%$ & $50 \%$ \\
\hline 9 & Mixed* & 4.1 & 1.2 & 142 & $23 \%$ & $50 \%$ \\
\hline
\end{tabular}

Note: Mixed sample usually correspond to BID and DID ores

These samples were tested using a rotational viscometer (bob in "infinite sea" configuration). The slurries were modeled as Bingham Plastic and the results for the whole slurry rheology are shown in the figures below.
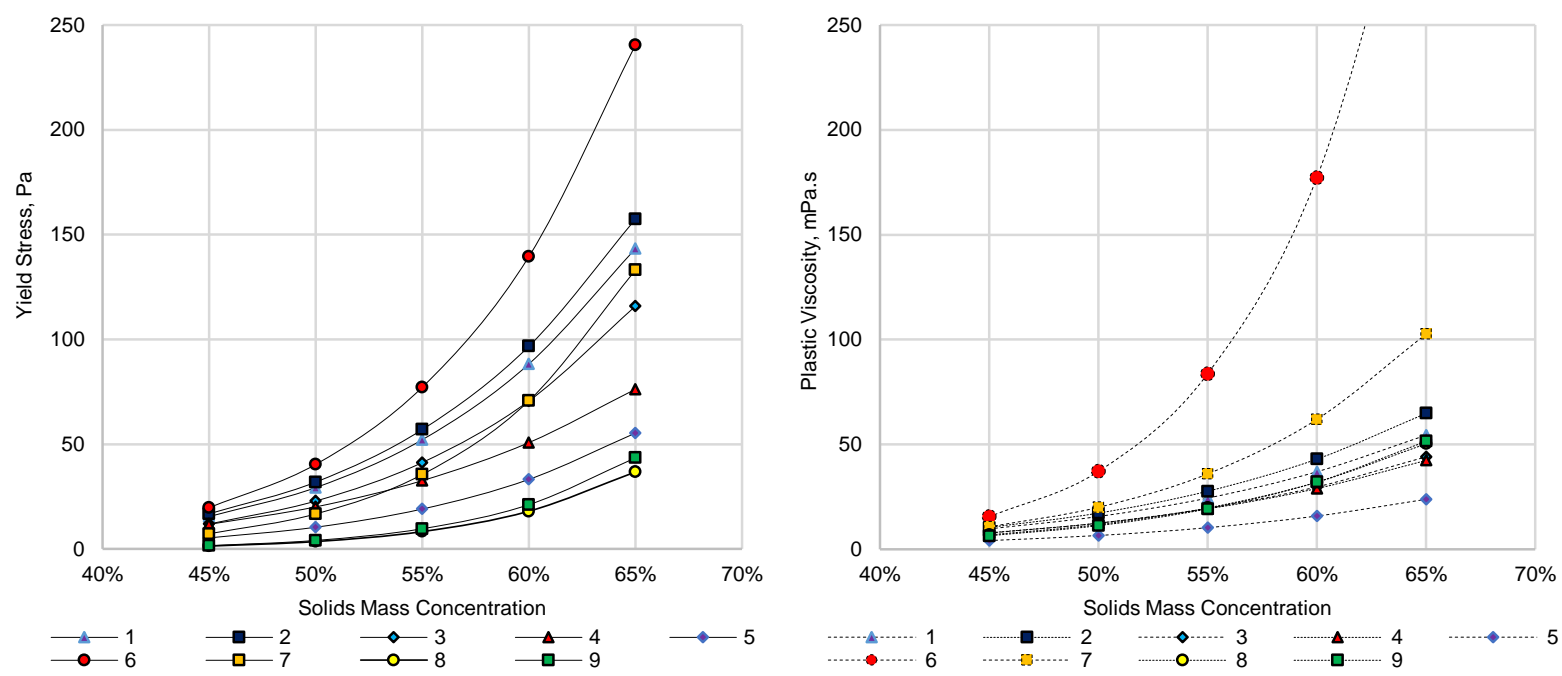

Figure 2 Whole slurry yield stress and plastic viscosity as function of mass solids concentration

All tests were done using process water from site. A common feature of all these sites is that water is brackish/salty, with conductivity above 500 and up to $10,000 \mu \mathrm{S} / \mathrm{cm}$. The $\mathrm{pH}$ is in the range 6 to 8 .

\section{$3 \quad$ Implementation challenges}

We believe that the challenges associated with the implementation of these intermediate to high concentration iron ore tailings pumping systems relate to three main issues: (1) Control of tailings process 
equipment; (2) selection of mechanical equipment; (3) understanding of slurry behavior, particularly in the laminar flow regime. Each of these issues is discussed further under separate headings below.

Factors that have a significant impact on the above issues and as a consequence affect the technical and financial feasibility of the high density tailings pumping system are primarily:

- Pumping distance and static head.

- Rheology variability.

These factors impact on the features of the mechanical equipment and pipeline and consequently the cost of the system. Longer pumping distances and higher static heads result in higher pumping pressures. High rheology variability can also result in higher temporary pumping pressures and higher pressure rated equipment. For lower pressure systems a typical lower cost option would be to operate with centrifugal pumps, which are generally limited to around $5000 \mathrm{kPa}$ maximum discharge pressure. This may be suitable for shorter pipeline systems (generally shorter than $5 \mathrm{~km}$ ) and reduced static head. For higher pressure systems the systems are generally more expensive and make use of positive displacement pumps and high pressure piping which allows for design up to $25000 \mathrm{kPa}$ discharge pressure. This would allow for implementation of longer pipeline systems or systems with higher static head.

\section{$4 \quad$ Rheology variability and design examples}

Designing iron ore tailings slurry pipeline systems for intermediate to high concentrations, where the slurry yield stress could be anywhere from 20 to $100 \mathrm{~Pa}$ (or more) requires special considerations compared to designs for low yield stress slurries. Figure 3 shows the laminar-turbulent transition velocity as a function of the slurry yield stress for three different slurry densities.

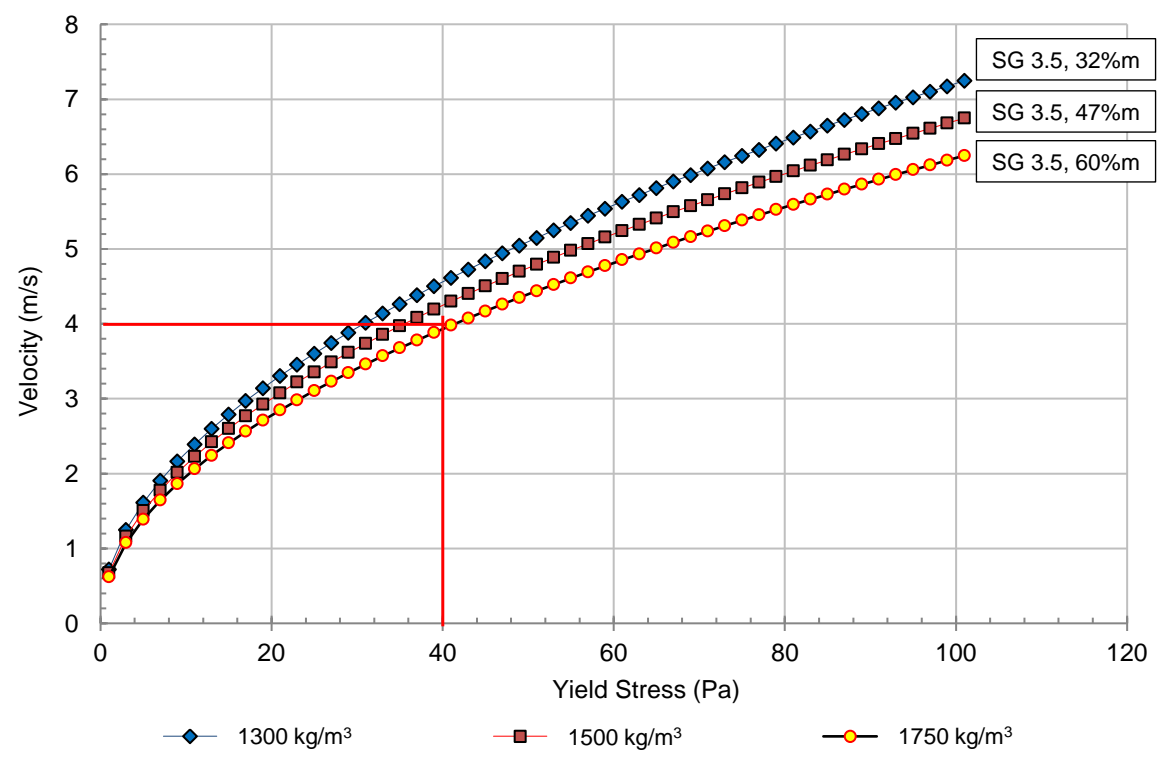

Figure 3 Laminar-Turbulent transition curves as function of yield stress

As seen in Figure 3, low yield stress slurries (below $20 \mathrm{~Pa}$ ) favor operation in the turbulent flow regime as the transition velocity is lower than $3 \mathrm{~m} / \mathrm{s}$ thus a cost effective design is usually feasible, depending upon the actual deposition velocity. At higher yield stress values, the laminar-turbulent transition velocity quickly increases. As the yield stress goes above 40 Pa the transition velocity increases above $4 \mathrm{~m} / \mathrm{s}$ which, in most cases, is not a good technical or economical option for slurry pipeline systems.

Although the design rheology is a key factor for the development of any slurry pipeline system, the rheology variability is a less obvious item. The bottom line is that the system must be able to cope with a range of 
rheology rather than a single rheology value or a narrow range that could be (nearly) impossible to achieve and control on full scale operation. Two examples are presented below to illustrate. The examples demonstrate the design considerations associated with two distinct cases in terms of yield stress range and potential pipeline flow regime, as shown in Figure 4:

- Example 1: Moderate to high yield stress - Potential for laminar and turbulent pipeline flow regime.

- Example 2: High to very high yield stress - Laminar pipeline flow regime only.

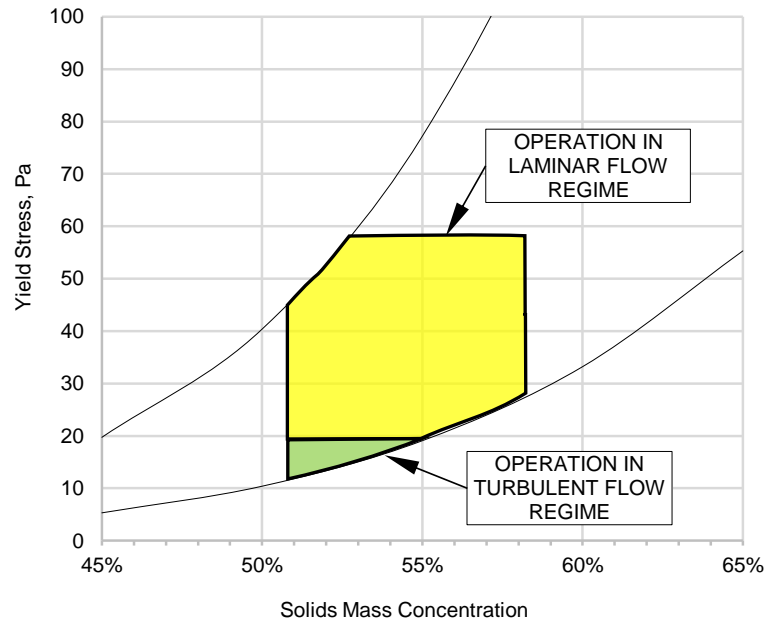

(a)

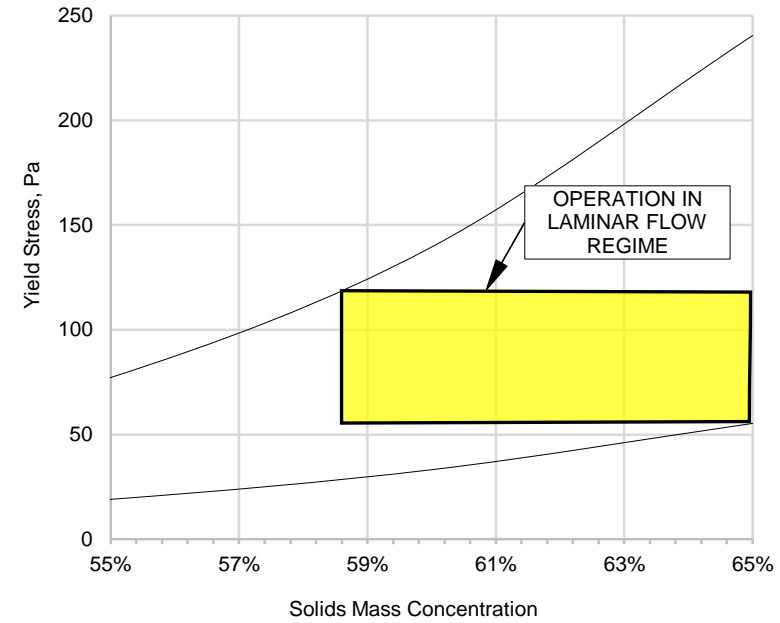

(b)

Figure 4 Rheology design range for two design examples; (a) Example 1; (b)Example 2

\subsection{Example 1}

In this case the target slurry concentration is $55 \%$, but the design considers a range of slurry concentration from 51 to $58 \%$. Based on the observed variability of the slurry samples tested, this translates to a yield stress range of approximately $12 \mathrm{~Pa}$ minimum to $>100 \mathrm{~Pa}$ maximum. In this case the slurry is produced by a thickener. A suitable thickener control system shall limit the maximum yield stress to approximately $60 \mathrm{~Pa}$ as shown in Figure 4.

Figure 5 shows the system design envelope (concentration range and pipeline velocity range) plotted relative to the turbulent deposition velocity limit and laminar-turbulent transition velocity limit for the upper and lower extremes of slurry rheology in this example (i.e. most viscous sample and least viscous sample). Depending on the viscous properties, the pipeline flow regime could be turbulent or laminar. The tailings pipeline system (pipe size and pumping pressure capacity) is selected to accommodate the operating envelope and rheology range. 

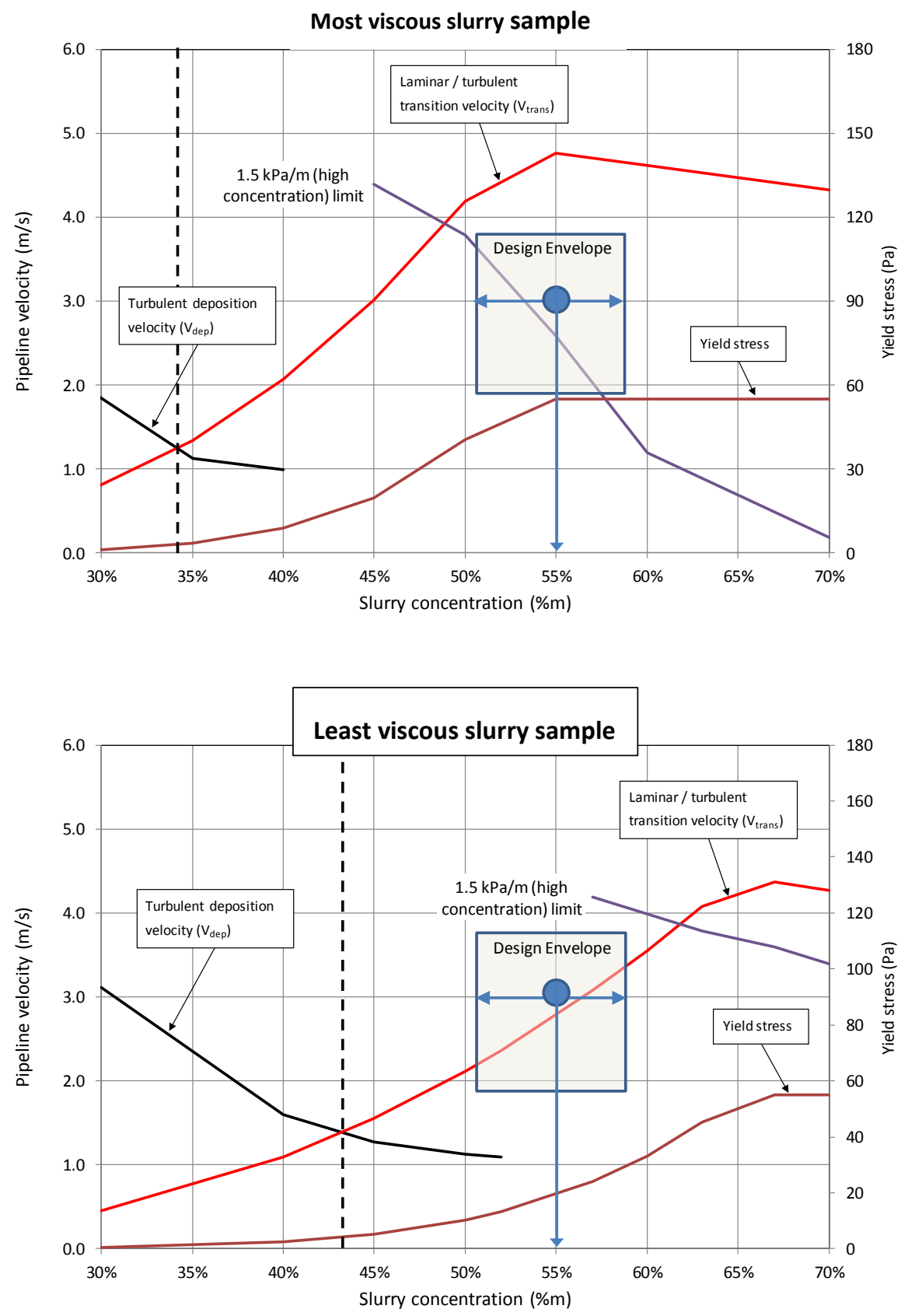

Figure 5 Example $1-$ Rheology design range for operation in laminar and turbulent flow regimes

\subsection{Example 2}

A similar situation happens when a different pipeline system is due to operate only at higher concentrations. In this case the pipeline system is designed to operate in the laminar flow regime only, however it must be able to handle significantly higher yield stress values than in the case of Example 1.

In this example, the system is designed to operate within a yield stress range of 55 to $120 \mathrm{~Pa}$ and in the laminar flow regime. Provided that a sliding bed is maintained, the system can operate at low velocities. These velocities are typically below the turbulent deposition velocities of similar slurries with lower rheology and for this reason it is important to control not only the upper rheology limit but also the lower rheology limit to ensure that any settled bed that develops in the pipeline will be transported (sliding rather than stationary).

Rheology control is also of paramount importance for a design scenario like in this example. Operating at rheology below the design range may result in stationary settled bed in the pipeline and above the design 
range may result in pressures exceeding the system design. In other words, it is important to maintain the design rheology range.

\section{$5 \quad$ Pipeline flow}

The examples and associated discussion presented above have highlighted that these thickened tailings systems operate in the intermediate to high concentration regions as defined in Figure 1 (and see Figure 5). These systems will predominantly operate at pipeline velocities below the laminar-turbulent transition velocity (i.e. in the laminar flow regime). This poses two (related) challenges for the designer:

- Evaluating the pipeline friction pressure gradient and thus system pumping pressures required.

- Evaluating the system stability (considering the potential for accumulation of settled coarse solids in the pipeline).

As shown in Table 2, these tailings slurries comprise a broad size distribution, from top size in the order of 1 $\mathrm{mm}$ to a substantial fraction of clay-size particles. When thickened, the clay component results in a carrier fluid (the mixture of water plus "fines") with yield pseudo-plastic or Bingham plastic characteristic.

For purposes of modelling the flow behavior of these slurries we choose to draw the division between "fine" and "coarse" particles at $45 \mu \mathrm{m}$. This is certainly not a rigid or clear division, but certainly in general agreement with others (Wilson et al., 2006 suggest $40 \mu \mathrm{m}$, Pullum et al., 2008 suggest "10 to $20 \mu \mathrm{m}$ ", and Pullum et al., 2015 suggest $40 \mu \mathrm{m}$ ). The coarse fraction of the slurry is characterized in terms of the solid and particle properties (solids density, particle size distribution, particle shape, maximum packing concentration, and potentially, solids porosity). The fines plus water carrier fluid is characterized in terms of its viscous properties and mixture density (i.e. fluid properties only). We then think of the thickened tailings as a slurry of the coarse solids fraction being conveyed in the carrier fluid.

A further consideration is the effect of the coarse solids on the viscous properties of the "whole" slurry. An overview of this phenomenon is provided by Paulsen et al., 2010, who reference the work of a number of preceding researchers. These references describe how the addition of "rheologically inert" coarse particles (e.g. sand or glass beads) to a slurry of "flocculating colloidal fines" results in an increase in the yield stress (the yield stress of the carrier fluid plus coarse particle slurry is greater than the yield stress of the carrier fluid alone). A similar increase in mixture plastic viscosity with addition of coarse particles is also observed.

Modelling the slurry pipeline flow behavior requires a knowledge of the viscous properties of the slurry in the pipeline. We describe under the heading "Segregation Under Laminar Flow Conditions" below, how the concentration of coarse particles varies over the pipe cross-section. We thus need to be able to evaluate the slurry yield stress and plastic viscosity (treating the slurry as a Bingham plastic) as a function of coarse solids concentration. Correlations for this effect are described in the references listed above.

Measuring the yield stress and plastic viscosity of the whole slurry (carrier fluid plus coarse fraction) at the delivered (process) coarse solids concentration in addition to the carrier fluid yield stress and plastic viscosity, provides one reference point for determining the correlation constant in the equations describing the relationship between coarse solids concentration and change in viscous properties.

\subsection{Segregation under laminar flow conditions}

Many researchers (Graham et al., 2002; Cooke, 2002; Talmon and Mastbergen, 2004), have described how moderately viscous non-Newtonian slurries, such as these thickened iron ore tailings, appear homogeneous and stable when static, but segregate under laminar pipe flow conditions. Under static conditions (e.g. a bucket of thickened tailings in the laboratory), the coarse particles are supported in the mixture by the yield stress of the carrier fluid. When the slurry is sheared however (e.g. stirred in the bucket or flowing in a pipe), the fine particle structure which produces the yield stress, is broken and the supporting effect of the yield 
stress is lost. In the absence of turbulence (laminar flow conditions) the coarse particles migrate downwards and form a settled bed in the pipe.

This sets up what can be simplistically visualized as a two-layer system, with lower layer the settled bed of coarse particles, and particle-lean upper layer of carrier fluid flowing above. This flow geometry for laminar flow of non-Newtonian plus coarse particle slurries has been observed and well documented. This has been predominantly with synthesized slurries where there is clear differentiation between the carrier fluid and the coarse particles, such as sand or crushed glass in polymer solutions (Graham et al., 2002; Pullum et al., 2004; Pullum et al., 2006; Matousek et al., 2015), sand and glass beads in kaolin clay slurry (Poloski et al., 2009). It can be reasonably inferred that that similar behavior will occur with thickened tailings with coarse particle component and more continuous particle size distribution.

Modelling laminar pipeline flow in terms of this two-layer geometry has also been well described by Pullum et al., 2004. This modelling can be applied to estimate the fraction of the pipe cross-section occupied by each layer, the velocity of each layer and the pipeline friction pressure gradient.

\subsection{Pipeline friction pressure gradient}

Pullum et al., 2004, have highlighted two potential errors that can be made if the potential for segregation of the slurry as described above has not been identified:

- The pipeline friction pressure gradient versus velocity relationship for segregating (two-layer) laminar flow lies well above that of the carrier fluid alone. Considering flow of the carrier fluid and assuming the coarse particles to be carried along "for free" results in substantial under-prediction of the pipeline pressure gradient.

- Secondly, they emphasize that the friction pressure gradient versus velocity relationship for segregated laminar pipeline flow looks very much like that of a homogeneous yield pseudo-plastic fluid. Ignoring the segregation of the slurry under laminar flow and using the pipeline pressure gradient data to fit rheological parameters (e.g. fitting the Buckingham equation for pipe flow relating bulk shear rate to wall shear stress through the Bingham plastic rheological parameters), will result in significant errors (applying equations which assume a homogeneous fluid and symmetrical velocity distribution to a scenario where this is not the case).

The above reference also provides a useful description of stratified (segregated) laminar flow and a proposed "non-Newtonian two-layer model". The calculation sequence very much follows that developed by Wilson, 1976 for application to sand - water slurries where the two-layer geometry (essentially, the position of the horizontal chord defining the boundary between the upper and lower layers) and upper and lower layer velocities, are determined by solving for a balance of forces acting on the two layers.

Consideration of the forces acting on the lower (settled bed) layer will identify whether the bed is sliding or stationary. If the bed is sliding, then the coarse solids are assumed to be contained (and transported) entirely in the bed layer. If the bed is stationary, then the coarse solids must be transported in the upper layer. In this case we assume that the flow regime in the upper layer must be turbulent (in order to suspend and transport the coarse particles). We make the assumption that the flow is just into the turbulent regime and so the upper layer velocity can be assumed to be equal to the laminar-turbulent transition velocity.

\subsection{In-Situ coarse solids concentration and system stability considerations}

A further outcome of the application of the two-layer model is a prediction of the in-situ concentration of coarse solids in the pipe. This is related directly to the area occupied by the lower layer, and the coarse solids packing concentration in the lower layer. This information can be applied to assessing the potential for pipeline blockages triggered by a change in the state of the system (change in flowrate, change in slurry concentration, change in carrier fluid yield stress, etc.). In particular, the impact on the pipeline friction 
pressure gradient should be considered as the pipeline system moves from one state to another.

For example: A reduction in carrier fluid yield stress could result in the upper layer flow regime changing from laminar to turbulent resulting in coarse solids being eroded from the lower layer and suspended in the upper layer. The extreme case would be a switch from slurry to water feed to the pipeline. It is possible that the friction pressure gradient for the coarse solids in turbulent suspension in the low-yield stress carrier is greater than for the original condition with thickened tailings feed.

Scenarios such as this should be checked to ensure that the pumping system is able to accommodate the transitions between operating states, and not only steady-state conditions.

\section{Control of tailings process equipment}

The rheology envelopes shown in Figure 4 requires a suitable control system of the tailings process equipment to ensure that the slurry committed to the pipeline is within the design envelope. Higher yield stress values would risk the operation of the thickener (e.g. rakes "bogging") or the pipeline (e.g. pipeline "stalling"). Lower yield stress values would jeopardize the operation of the pipeline (e.g. blockages, accelerated bottom wear in pipes, etc.). Although there are different alternatives for achieving this goal, the implementation is specific to each particular project conditions and slurry characteristics. In all these cases the aim is to be able to control the thickener and monitor the rheology being delivered. The adequate solution for each particular project shall be agreed with the process equipment supplier.

\section{$7 \quad$ Mechanical equipment selection}

The selection of suitable mechanical equipment is paramount for dealing with these extreme rheological properties in order to provide reliable and efficient tailings pipeline system operation. This is essentially operation without pipeline blockage and with safe pressure containment for all conditions in the expected design envelope (varying tailings properties and flowrates/throughput). To achieve this:

- The pumps must be able to generate the required pumping pressure for all operating conditions.

- The piping and all other components must safely contain the system pressures for all operating conditions.

- The system controls and operation must avoid excursions outside of the design (safe) operating envelope.

The power draw and pumps discharge pressure in these examples could be up to twice the values when the rheological properties are at the lowest end of the design range. From this point of view, most of these systems lend themselves to utilize positive displacement pumps rather than centrifugal pumps. That is not due to the high rheological properties considered, but due to the high variations of pump discharge pressure required.

The upside of these arrangements, especially in the case when the system is operated only in laminar flow regime, is that it is able to accommodate significant flow/throughput variations when compared to traditional slurry pipeline systems operating in turbulent flow regime.

\section{Conclusions}

This paper has described the design challenges associated with the significant rheology variability seen in intermediate to high concentration thickened iron ore tailings slurries. The following are the key points made:

- The design of these iron ore tailings pipeline system must consider the full range of slurry properties as these can change significantly over long and short periods. 
- Prediction of the pipeline friction pressure gradient and in-situ coarse solids concentration for these slurries requires; reliable characterization of the carrier fluid rheology, appreciation of how the coarse particles modify the viscous properties of the carrier fluid, and a pipeline flow model which reflects the conditions in the pipe, in particular, segregation under laminar flow conditions.

- It is of paramount importance limiting the maximum and minimum slurry yield stress the upstream process equipment (e.g. thickener) can produce. Although there are different alternatives for achieving this goal, the implementation is specific to the slurry characteristics and the type of process equipment and ancillaries. This provides a way of reducing the rheology design range, allowing for less conservative pumping equipment selection. This can significantly affect the selection and sizing of thickening equipment, pumping equipment and pipeline sizing and pressure rating.

\section{References}

Cooke, R. 2002, 'Laminar Flow Settling: The Potential for Unexpected Problems', Proceedings of the 15th International Conference on Hydrotransport. BHRA.

Distribution Suspensions Using a Small Pipe Viscometer, Proceedings of the 14th International Conference on Transport and Sedimentation of Solid Particles.

Goosen, P., Paterson, A. 2014, 'Trends in Stationary Deposition Velocity with Varying Slurry Concentration Covering the Turbulent and Laminar Flow Regimes', Proceedings of the 19th International Conference on Hydrotransport. BHRA.

Graham, L., Hamilton, R., Rudman, M., Strode, P. and Pullum, L. 2002, 'Coarse Solids Concentration Profiles in Laminar Pipe Flow', Proceedings of the 15th International Conference on Hydrotransport. BHRA.

Matousek V., Penik, V., Pullum L., Chryss, A. 2015, 'Experimental Study of Bed Friction in Stratified Flow with Viscoplastic Carrier in Pipe', Proceedings of the 17th International Conference on Transport and Sedimentation of Solid Particles.

Paulsen, E., Sumner, R.J., Sanders, R.S. 2010, 'The effect of Coarse Particle Addition on Rheology of Fine Clay Slurries', Proceedings of the 18th International Conference on Hydrotransport. BHRA.

Poloski, A.P., Bonebrake, M.L., Casella, A.M., Johnson, M.D., Toth, J.J., and Adkins, H.E. 2009, 'Deposition Velocities of Non-Newtonian Slurries in Pipelines: Complex Simulant Testing', Report prepared for the U.S. Department of Energy under Contract DE-AC0576RL01830.

Pullum, L., Chryss, A., Graham, L. and Slatter, P. 2008, 'A Technique to Obtain the Underlying Carrier Fluid Rheology from Wide Size'.

Pullum, L., Chryss, A., Graham, L., Matousek, V. and Panik, V. 2015, 'Modelling Turbulent Transport of Solids in Non-Newtonian Carrier Fluids Applicable to Tailings Disposal', Proceedings of the 15th International Conference on Transport and Sedimentation of Solid Particles.

Pullum, L., Graham, L., Rudman, M., Aldham, B., Hamilton, R. 2006, 'The Ups and Downs of Paste Transport', Proceedings of the 9th International Seminar on Paste and Thickened Tailings, Australian Centre for Geomechanics, Perth.

Pullum, L., Graham, L., Slatter, P. 2004, 'A Non-Newtonian Two-layer Model and its Application to High Density Hydrotransport', Proceedings of the 16th International Conference on Hydrotransport. BHRA.

Talmon, A., Mastbergen, D. 2004, 'Solids Transport by Drilling Fluids: Concentrated Bentonite-Sand Slurries', Proceedings of the 12th International Conference on Transport and Sedimentation of Solid Particles.

Wilson, K.C. 1976, 'A Unified Physically-based Analysis of Solid-liquid Pipeline Flow', Proceedings of the 4th International Conference on Hydrotransport. BHRA.

Wilson, K.C., Addie, G.R., Sellgren, A. and Clift, R. 2006, 'Slurry Transport Using Centrifugal Pumps' (3rd edition), Springer, New York, USA. 